\title{
Effects of ColdArc welding parameters on the tensile strengths of high strength steel plate investigated using the Taguchi approach
}

\author{
S. D. Sabdin*1, N. I. S. Hussein ${ }^{1}$, M. K. Sued ${ }^{1}$, M.S. Ayob ${ }^{1}$, M.A.S.A Rahim ${ }^{1}$ and \\ M.Fadzil $^{2}$ \\ ${ }^{1}$ Faculty of Manufacturing Engineering, Universiti Teknikal Malaysia Melaka, \\ Hang Tuah Jaya, 76100 Durian Tunggal, Melaka, Malaysia \\ Phone: +60192146061 \\ "Email: saifulkdh@yahoo.com \\ ${ }^{2}$ Centre of Advanced Manufacturing and Material Processing (AMMP Centre), \\ Faculty of Engineering, University of Malaya, 50603 Kuala Lumpur, Malaysia
}

\begin{abstract}
The objective of this study is to investigate the effect of process parameters on ColdArc welding of high strength steel plate using $1.2 \mathrm{~mm}$ diameter mild steel welding wire. A Taguchi Design of Experiments (DOE) method with grey relational analysis approach was selected for data collection and optimization. 9 experiments were conducted following the L9 $\left(3^{3}\right)$ Taguchi Orthogonal Array Design. The best result from the experiments for tensile strength was obtained for welding parameters of $70 \mathrm{~A}$ (current), $17.6 \mathrm{~V}$ (voltage) and 800 $\mathrm{mm} / \mathrm{min}$ welding speed. Based on the results, the Taguchi analysis predicted the optimised tensile strength would be obtained when the welding current, welding voltage and speed are at $70 \mathrm{~V}, 17.6 \mathrm{~A}$ and $600 \mathrm{~mm} / \mathrm{min}$, respectively. Thus, most significant parameters for tensile properties of cold rolled steel is welding speed (37\%), voltage (34 \%) and current (28\%). These factors are critical in determining the tensile strength, where increasing the welding speed reduces the heat input. However, decreasing the heat input by lowering the welding voltage resulted in bad weld bead formation.
\end{abstract}

Keywords: ColdArc; Arc welding; GMAW; SPCC; Automotive.

\section{INTRODUCTION}

The ColdArc welding method is a prospective welding process for the sheet metal industry. It is a modification of the gas metal arc welding (GMAW) technology. The method offers narrow fabrication tolerances, improved weld quality and increased welding productivity [1]. The ColdArc process is characterised by the reduced heat input, obtainable by modifying the 'short arc' process, which is only possible with recent advancements in electrical sources for welding [2]. As compared to a typical short arc process, the power output at the time of arc re-ignition is much lower in the ColdArc welding. Furthermore, the power at re-ignition is not constant. It decreases dynamically in a controlled manner and once the arc is stabilised, the power is increased by pulsating it until the required power necessary to melt the wire at the end of the electrode is achieved [3]. 
Heat input is one of the most important process parameters in controlling weld response [4]. It refers to the electrical energy supplied by the welding arc to the weldment. As manufacturers are adopting the use of light and thin materials, the issue of heat input in welding becomes critical [5]. Welding of thin sheet metal products is very susceptible to distortion and deformation, caused by the thermal expansion of the material due to the welding heat input. Past studies have focused on GMAW welding of thin plate, mostly selecting the parameters of welding current, voltage and speed [6-11]. It was found in most studies that the welding speed was the most influential parameter in determining the weld mechanical properties for tensile strength and hardness due to the weld bead formed. Furthermore these parameters would also influence the corrosion resistance, the size of the weld bead and the extent of grain coarsening obtained in these weld joints [12-14].

Recent advancement in automotive technology has seen the increasing use of cold rolled steel plates for high-strength automotive steel applications. These transformations induced plasticity and twinning induced plasticity steels, having readily achieving sheetformability, offers improved vehicle structure with high impact and shock resistance in vehicle collisions [7-8]. However, despite their excellent tensile properties, the commercialization of high-strength steel has been sluggish due to issues of deteriorated surface quality, delayed fracture, and liquid metal embrittlement[9-14]. Usage of high strength steel is appealing to automotive manufacturers since the required structural strength can be obtained using thinner materials, thus reducing the weight and improves the overall performance and fuel economy of the vehicle. Prior to the usage of high-strength highmanganese steels in automotive applications, the production and further processing to cold strip is a point of interest. Due to the high strength, it is possible to reduce the weight of the car, whereas the increase in ductility allows for a more complex car design [15-16].

The Taguchi design method, developed by Genichi Taguchi, applies fractional factorial test designs called Orthogonal Arrays (OA) that aims to reduce the number of experiments to be conducted [17]. It is an efficient and systematic technique for optimizing designs for performance, quality and cost [16]. The selection of a suitable OA depends on the number of control factors and their levels. Using OA design allows the evaluation of multiple process variables simultaneously affecting the performance characteristic, while minimizing the number of test runs. For example, for four parameters at three levels, the traditional full factorial design would require 34 or 81 experiments. In the Taguchi L9 OA, however, the required experimental runs are reduced to 9 runs. Rizvi et al. (2018) optimized the process parameters that affect the weldability of SS304 austenitic steel, and in their result, they mentioned that wire feed speed the most significant effect followed by voltage and gas flow rate effect on tensile strength of the welded joint[18] based on Taguchi method. Rizvi et al. (2017) optimized the process parameters that affect the weldability of IS2062, and in their result, they mentioned that welding current and voltage have significant effects whereas gas flow rate has an insignificant effect on tensile strength of the welded joint[19]. Ghosh et al. (2016) optimized the gas metal arc welding process parameters on 316L steel by Grey relational based Taguchi method, and the current was found to be more significant parameter than gas flow rate influencing the strength of the welded joints [20]. Datta et al. [2008] applied Taguchi technique followed by GRA to solve multi-response optimization problem during the submerged arc welding[21].

The objective of this study is to investigate the effect of current, voltage and welding speed on the tensile strength for high strength steel welded using the ColdArc method. Two 
plates of steel high strength steel of dissimilar thicknesses would be welded by direct fusion welding using the ColdArc welding process. The experiments would be conducted following the Taguchi L9 OA, and the results would be analysed accordingly from the Taguchi response table, ANOVA and contour plot graphs. Mechanisms related with improvement of tensile properties were investigated by focusing on welding parameters that have been established through design method.

\section{METHODS AND MATERIALS}

\section{Materials}

In this research, the material chosen was high strength steel plate that following the JIS G3141 specifications shown in Table 1. It offers very good formability and comparatively high strength due to their unique combination of strength and elongation. This is because of having manganese elements that suitable for the applications in the automotive industry [13].

Table 1. Chemical composition of material

\begin{tabular}{lcccccccccccc}
\hline Elements & $\mathrm{C}$ & $\mathrm{Si}$ & $\mathrm{Mn}$ & $\mathrm{P}$ & $\mathrm{S}$ & $\mathrm{Cr}$ & $\mathrm{Mo}$ & $\mathrm{N}$ & $\mathrm{Al}$ & $\mathrm{Cu}$ & $\mathrm{Co}$ & $\mathrm{Fe}$ \\
JIS G3141 & 0.045 & 0.009 & 0.2 & 0.01 & 0.006 & 0.006 & 0.006 & 0.013 & 0.051 & 0.013 & 0.024 & Bal. \\
\hline
\end{tabular}

\section{Design of Experiments}

Three factors at three levels are selected for investigation, which are the welding current (A), welding voltage and welding speed (WS). The values at (-1) were determined from trial runs while the values at levels (0) and (1) are based on adjusted parameters from past studies [1,18-19]. An L9 $\left(3^{3}\right)$ OA was used, and the complete design of experiment is shown in Table 2 and Table 3. Each experiment was repeated thrice for statistical reliability.

Table 2. The selection of response and variable in the experimental design.

\begin{tabular}{cccc}
\hline \multirow{2}{*}{ Factors } & \multicolumn{3}{c}{ Levels } \\
\cline { 2 - 4 } & -1 & 0 & 1 \\
\hline Welding current (A) & 70 & 75 & 78 \\
Welding voltage (V) & 7.5 & 16.8 & 17.6 \\
Welding speed(mm/min) & 400 & 600 & 800 \\
\hline
\end{tabular}


Table 3. L9 orthogonal array of the experiments

\begin{tabular}{cccc}
\hline Experiment & $\begin{array}{c}\text { Current } \\
(\mathbf{A})\end{array}$ & $\begin{array}{c}\text { Voltage } \\
(\mathbf{V})\end{array}$ & $\begin{array}{c}\text { Welding Speed } \\
(\mathbf{m m} / \mathbf{m i n})\end{array}$ \\
\hline 1 & 70 & 7.5 & 400 \\
2 & 70 & 16.8 & 600 \\
3 & 70 & 17.6 & 800 \\
4 & 75 & 7.5 & 600 \\
5 & 75 & 16.8 & 800 \\
6 & 75 & 17.6 & 400 \\
7 & 78 & 7.5 & 800 \\
8 & 78 & 16.8 & 400 \\
9 & 78 & 17.6 & 600 \\
\hline
\end{tabular}

Analysis of S/ $\mathrm{N}$ ratio: In Taguchi technique, the term 'signal' represents the desirable value for the output characteristic and the term 'noise' represents the undesirable value for the output characteristic. These points indicate the best parameters that would give the best or optimised value of tensile strength. $\mathrm{S} / \mathrm{N}$ ratios for different conditions are:

Where

$$
\begin{aligned}
& \mathrm{S} / \mathrm{N} \text { ratio for }(\text { Nominal is better })=10 \log \left(\sum \frac{\mu^{2}}{\sigma^{2}}\right) \\
& \mathrm{S} / \mathrm{N} \text { ratio for }(\text { Smaller is better })=-10 \log \left(\sum \frac{y^{2}}{n}\right) \\
& \mathrm{S} / \mathrm{N} \text { ratio for (bigger the better) }=-10 \log \left(\frac{1}{n} \sum \frac{1}{y^{2}}\right)
\end{aligned}
$$

$$
\begin{aligned}
& n=\text { number of tests } \\
& \mu=\text { mean or average } \\
& \sigma=\text { standard deviation } \\
& y=\text { response factor }
\end{aligned}
$$

\section{Experiment Setup}

The steel plate samples were arranged to be welded in a lap joint configuration. This joint arrangement was chosen for ease of welding using the robotic arm of the GMAW ColdArc welding machine (Germany: EWM, model: alpha Q 352 puls), as shown in Figure 1. The dimensions of each plates were $250 \mathrm{~mm} \times 50 \mathrm{~mm} \times 0.8 \mathrm{~mm}$ (Plate 1) and $250 \mathrm{~mm} \times 50 \mathrm{~mm}$ $\mathrm{x} 1 \mathrm{~mm}$ (Plate 2). The filler rod used was an ER70S-6 mild steel filler rod with a diameter of $1.2 \mathrm{~mm}$. This mild steel wire is a high-performance filler material, especially for robotic or mechanized welding, and is commonly used for construction, shipbuilding, automotive parts and fabrication. It can produce a smooth constant arc with low spatter and smooth surface finish in the weld bead. Figure 2 shows the schematic of the sample prepared for tensile strength measurements. Tensile testing were conducted using a universal testing machine (UTM), capable of maximum load of $100 \mathrm{kN}$ at $4 \mathrm{~mm} / \mathrm{min}$ speed of stretch. Each parameter were repeated three times during the experiment. The results obtained was then analysed using Minitab ${ }^{\circledR}$ Statistical Software version 17. 


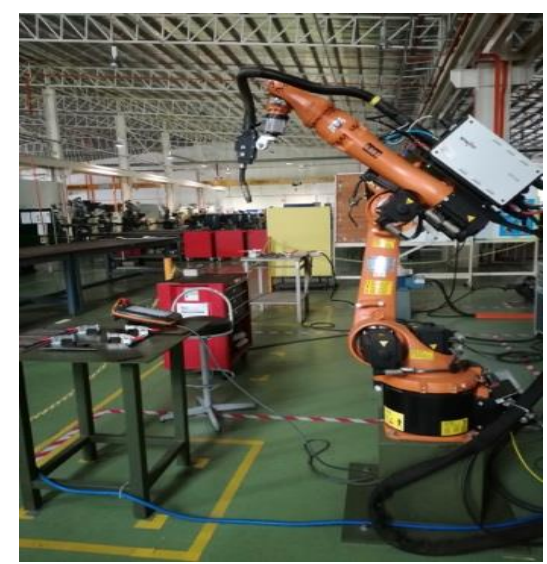

Figure 1. The robotic arm of gas metal arc welding type KRC4

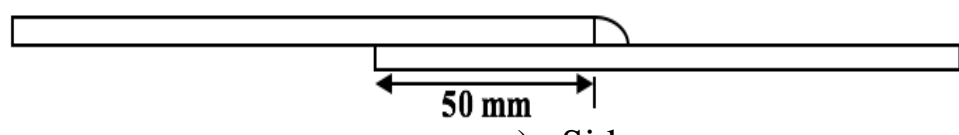

a) Side

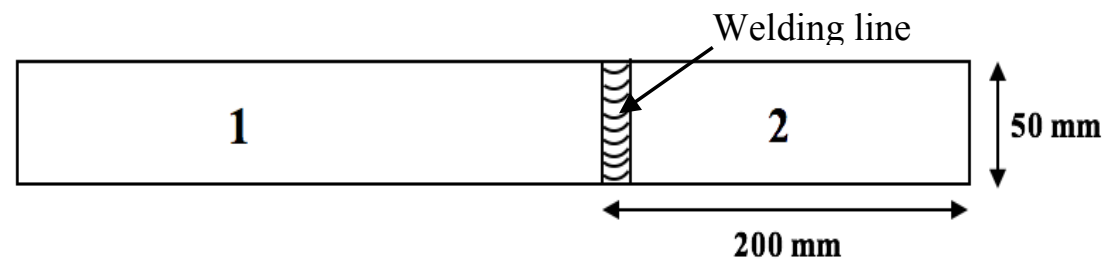

b) Top

Figure 2. Schematic of lap joint of the specimen prepared for tensile test[20].

\section{RESULTS AND DISCUSSION}

Figure 3 shows example of the resulting ColdArc weld of the conducted experiment. Generally, a constant weldment with good cap formation was obtained. Table 4 shows the average results of the tensile strength. The highest tensile strength obtained for experiment 3 is $244 \mathrm{MPa}$ while the lowest value is $195 \mathrm{MPa}$ for the experiment 5.

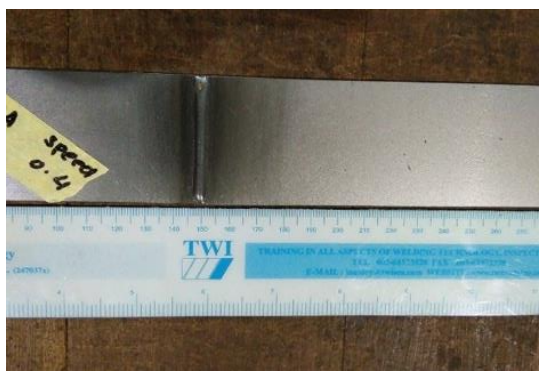

Sample 1

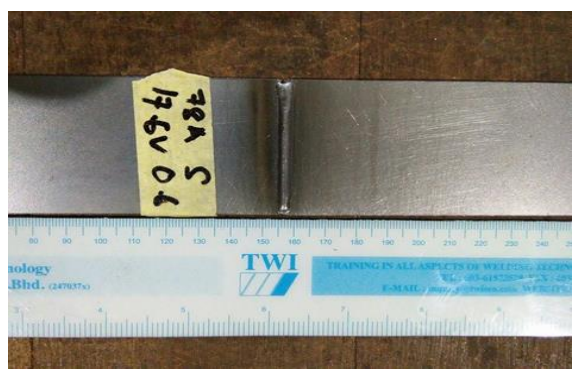

Sample 9

Figure 3. A sample photograph of the welded joint 
Table 4. Observed result of tensile strength

\begin{tabular}{ccccc}
\hline Sample & $\begin{array}{c}\text { Welding } \\
\text { Current } \\
(\mathbf{A})\end{array}$ & $\begin{array}{c}\text { Welding } \\
\text { Voltage } \\
(\mathbf{V})\end{array}$ & $\begin{array}{c}\text { Welding } \\
\text { Speed } \\
(\mathbf{m m} / \mathbf{m i n})\end{array}$ & $\begin{array}{c}\text { Average Tensile } \\
\text { Strength } \\
\text { (MPa) }\end{array}$ \\
\hline 1 & 70 & 7.5 & 400 & 228 \\
2 & 70 & 16.8 & 600 & 240 \\
3 & 70 & 17.6 & 800 & 244 \\
4 & 75 & 7.5 & 600 & 240 \\
5 & 75 & 16.8 & 800 & 195 \\
6 & 75 & 17.6 & 400 & 231 \\
7 & 78 & 7.5 & 800 & 210 \\
8 & 78 & 16.8 & 400 & 210 \\
9 & 78 & 17.6 & 600 & 236 \\
\hline
\end{tabular}

\section{Analysis of Variance (ANOVA)}

ANOVA method enables the computation of the contribution of each process parameter to the overall response variation. It is used to determine the significance of each input parameters. In this study, the significance of welding parameters of current, voltage and welding speed was determine using Minitab® Statistical Software version 17. The ANOVA was then calculated to analyse the importance of best process parameters. Table 5 indicate that welding speed is the most significant for welding process. The welding speed has a significant effect on the performance characteristic when the $\mathrm{F}$ value is large.

Table 5. ANOVA for average tensile strength

\begin{tabular}{ccccccc}
\hline Source & $\begin{array}{c}\text { Degree of } \\
\text { freedom }\end{array}$ & $\begin{array}{c}\text { Sum of } \\
\text { Squares }\end{array}$ & Mean & F-Value & P-value & $\begin{array}{c}\text { Percentage } \\
\text { Contribution }\end{array}$ \\
\hline Current & 2 & 599.4 & 299.7 & 2.88 & 0.258 & 28.24 \\
Voltage & 2 & 730.4 & 365.2 & 3.51 & 0.222 & 34.41 \\
Welding & 2 & 792.5 & 396.3 & 3.81 & 0.208 & 37.35 \\
speed & 2 & 208 & 104 & & & \\
Error & 2 & 2330.4 & & & & \\
Total & 8 & & & & & \\
\hline
\end{tabular}

Figure 4 shows the percentage factor contribution, obtained from the ANOVA analysis, on tensile strength material. The percentage contribution by each welding parameter to the total sum of the squared deviations SST can be used to evaluate the importance of the welding parameter change on the performance characteristic. The highest contribution was 
the welding speed (37.35\%), followed by Voltage (34.41\%) and lastly by the Current (28.24\%). According to ANOVA results, the most dominant effect is welding speed is similar with the finding by S. A. Rizvi and S. P. Tewari (2018)[18].

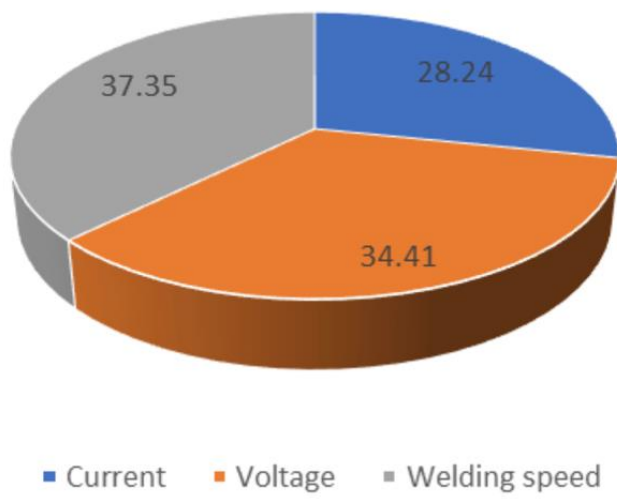

Figure 4. Effects factors parameter of tensile strength

\section{Signal-to-noise ratio}

Table 6 shows the S/N ratio analysis for tensile strength obtained from the results of the Taguchi method analysis. The $\mathrm{S} / \mathrm{N}$ ratio is the ratio of the mean (signal) to the standard deviation (noise).The value of delta was the highest for the welding speed, followed by the voltage and then current. This indicates that the welding speed is ranked first, followed by the voltage and current. Therefore, the most significant parameter affecting the tensile strength of the high strength steel welded by ColdArc GMAW is the welding speed.

Table 6: S/N ratio of tensile strength

\begin{tabular}{cccc}
\hline Level & $\begin{array}{c}\text { Welding } \\
\text { Current(A) }\end{array}$ & $\begin{array}{c}\text { Welding } \\
\text { Voltage(V) }\end{array}$ & $\begin{array}{c}\text { Welding } \\
\text { Speed(mm/min) }\end{array}$ \\
\hline 1 & 47.5 & 47.06 & 46.95 \\
2 & 46.87 & 46.61 & 47.56 \\
3 & 46.79 & 47.49 & 46.65 \\
Delta & 0.72 & 0.88 & 0.91 \\
Rank & 3 & 2 & 1 \\
\hline
\end{tabular}

The $\mathrm{S} / \mathrm{N}$ ratio is generally used is nominal is better, smaller is better and bigger is better The Equation (3) to the response chosen is the bigger the better characteristics, which indicates high tensile strength is desirable. Figure 5 shows the main effects plots for $\mathrm{S} / \mathrm{N}$ ratio of tensile strength results for the current, voltage and welding speed within the mean range of 46.50 to 47.50 . The response plot shows that the optimised condition is at $70 \mathrm{~A}$ welding current, voltage value of $17.6 \mathrm{~V}$ welding voltage and $600 \mathrm{~mm} / \mathrm{min}$ welding speed. Similar trends were observed for the three analysis of mean effects $\mathrm{S} / \mathrm{N}$ ratio. The highest peak was observed at the first point for the Current, the $3^{\text {rd }}$ point of Voltage and the $2^{\text {nd }}$ peak of welding speed. 


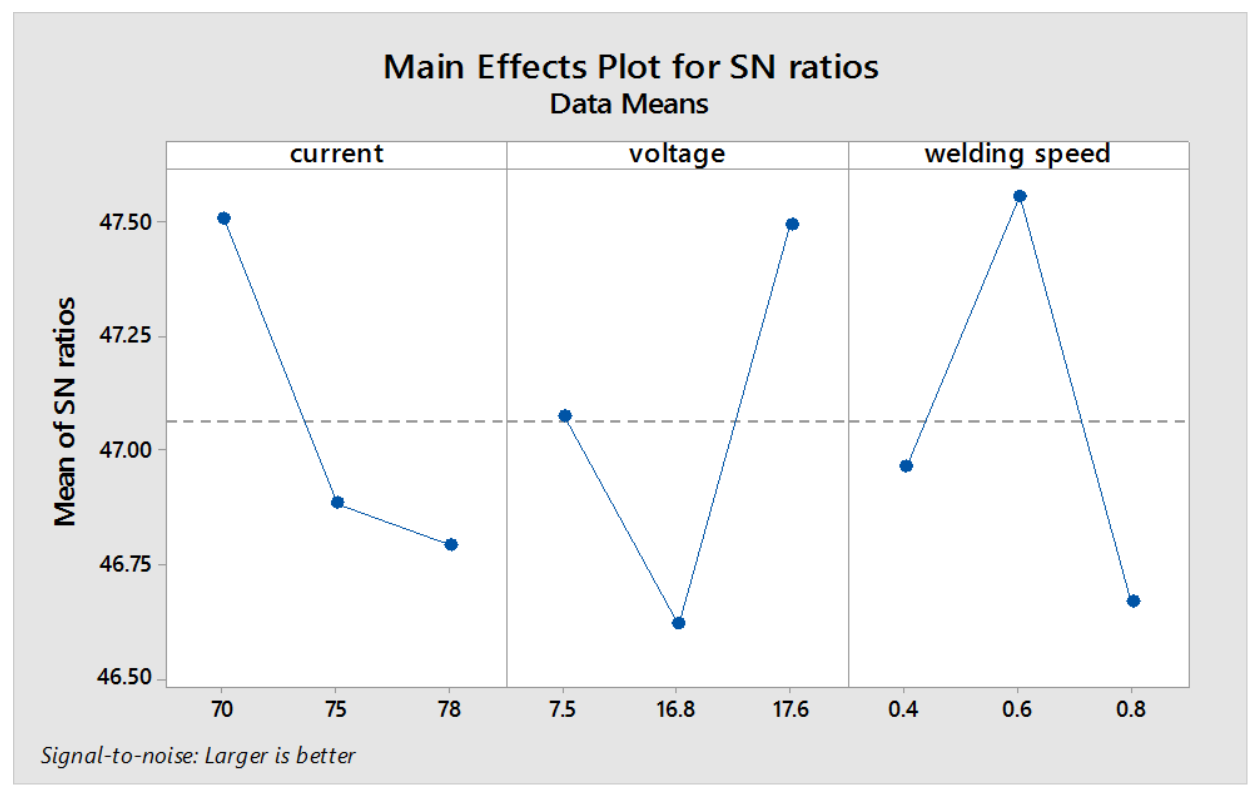

Figure 5: Effects plot for S/N ratio of tensile strength

\section{Contour plot relationship three parameter}

Figure 6 shows the contour plots are topographical maps drawn from three-dimensional data. Welding speed is represented on the horizontal axis and a second variable is welding voltage represented on the vertical axis. The welding current is represented by a colour gradient and isolines. These plots shows minimums and maximum in a set of trivariate data three parameter. The response graph for each factor at each level. It is clear that when the voltage increase, the current will increases. On the contrary simultaneous increase of welding speed result in increase of tensile strength. The higher the weld speed the lower is the irradiation time causing low heat input to the weld zone.

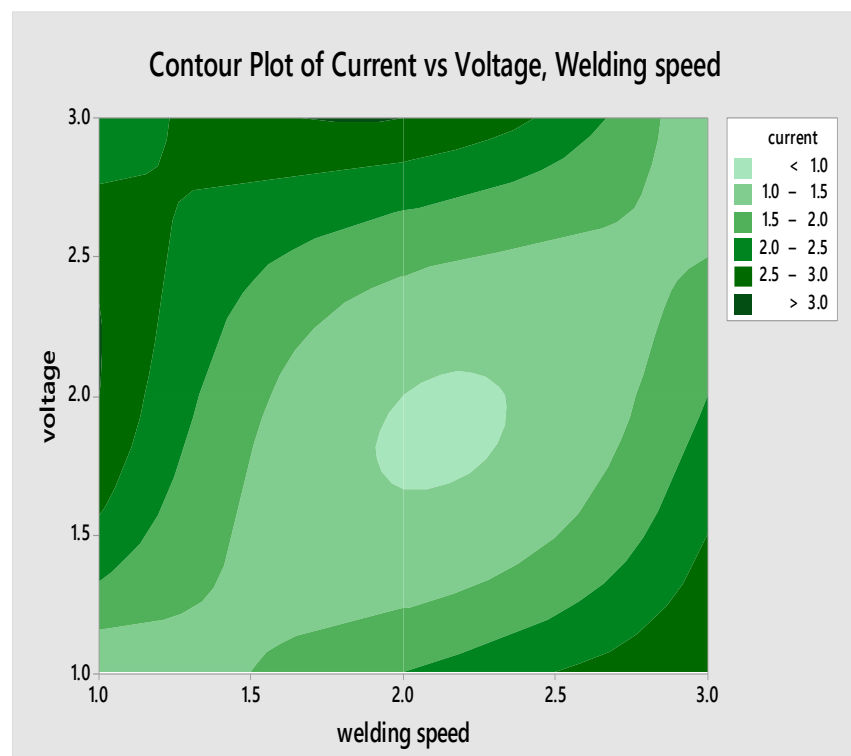

Figure 6. Iteration of current vs voltage and welding speed of tensile strength 
K. Japtap et al (2017) reported that tensile and yield strength increased at high welding current $210 \mathrm{~A}$ and welding speed $3 \mathrm{~mm} / \mathrm{min}$. This work was conducted on the IS 2062 steel grade. This behaviour was attributed to the fact that by increasing welding speed causing decrease in the heat input. This is proven through the increment of the mechanical properties [25]. This study also correlate K. Bang et al (2008) reported variation of welding parameters resulted tensile properties when heat input was decrease by increase welding speed, and by increasing voltage, the tensile strength of weld metal increase[26].

\section{CONCLUSIONS}

In general, it was found that dissimilar high strength steels plates in a lap joint configuration can be successfully welded using the ColdArc technology. The resulting weldment was consistent with minimal spatter levels. Dissimilar thickness joining can be found in the automotive industry, thus making the ColdArc technology relevant to these sectors. The following conclusions can be drawn from this study:

- ColdArc technology using the Gas Metal Arc Welding (GMAW) platform can be used to weld high strength steel sheet. However proper selection of welding parameters is required to obtain good quality welds. This can be obtained by screening processes as well as suitable control of the welding conditions and environments.

- The tensile strength of the welded joint in the high strength steels is obtained for the sample No. 3 corresponding to $70 \mathrm{~A}$ welding current, $17.6 \mathrm{~V}$ welding voltage and 800 $\mathrm{mm} / \mathrm{min}$ welding speed.

- $\quad$ The main mean effects plots of $\mathrm{S} / \mathrm{N}$ ratio for optimum parametric were obtained when the welding current, welding voltage and speed were at $70 \mathrm{~V}, 17.6 \mathrm{~A}$ and $600 \mathrm{~mm} / \mathrm{min}$, respectively.

- $\quad$ The welding speed (37\%) and welding voltage (34\%) gave high impact on the tensile strength properties. These two factors should be considered in obtaining the desired tensile strength properties were related with the microstructural change. It was found that increasing the welding speed decreases the heat input. However, lowering the welding voltage would also result in lower heat input but the weld bead formed is not very good.

\section{ACKNOWLEDGEMENTS}

The authors would like to thank the Faculty of Manufacturing Engineering, Universiti Teknikal Malaysia Melaka (UTeM), Advanced Technology Training Center (ADTEC) Batu Pahat and Scientific and Industrial Research Institute of Malaysia (SIRIM), Shah Alam for their technical support throughout this research work. The first author gratefully acknowledges the scholarship support provided by the Public Service Department Malaysia, under the Hadiah Latihan Persekutuan (HLP) programme. 


\section{REFERENCES}

[1] S. F. Goecke.Low Energy Arc Joining Process for Materials Sensitive to Heat. EWM Hightec Welding GmbH .2005; 3.

[2] J. P. Bergmann, J. Wilden, S. Reich, S.-F. Goecke. Methods and solutions for joining plates made from different metals using voltaic arc welding welding International .2009;23(12):37-41.

[3] M. De Dompablo.New solutions in coldArc and forceArc welding technology. Welding International. 2013;27: 37-41.

[4] M. H. K. Chavan, D. M. S. K. Mr. Gunwant D. Shelake.Effect Of Heat Input And Speed Of Welding On Distortion In Mig Welding.International Journal of Industrial Engineering Researc and Development (IJIERD).2012; 3(2): 42-50.

[5] S. D. Sabdin, N. I. S. Hussein, M. K. Sued, M. N. Ayof.Heat Sensitivity on ASTM A36 mild steel plate joint using low energy arc joining welding. Proceedings of Mechanical Engineering Research Day 2017;2017:358-359.

[6] R. K. Kesharwani, S. K. Panda, S. K. Pal. Multi Objective Optimization of Friction Stir Welding Parameters for Joining of Two Dissimilar Thin Aluminum Sheets.Procedia Materials Science.2014;6:178-187.

[7] M. Kang, J. Park, S. Su, D. Ahn, H. Seop, W. Tae, K. Chin, S. Lee. Materials Science \& Engineering A Dynamic tensile behavior of twinning-induced plasticity / lowcarbon ( TWIP / LC ) steel clad sheets bonded by hot rolling.Materials Science \& Engineering A. 2017;700:387-396.

[8] J. Park, M. Kang, S. S. Sohn, J. S. Kim, H. S. Kim, W. T. Cho, S. Lee.Tensile properties of cold-rolled TWIP-cored three-layer steel sheets.Materials Science and Engineering A. 2017;686:160-167.

[9] G. Frommeyer,U.Brüx,P.Neumann. Supra-Ductile and High-Strength ManganeseTRIP/TWIP Steels for High Energy Absorption Purposes.Isij International.2003;43(3):438-446.

[10] H. Idrissi, K. Renard, D. Schryvers, P. J. Jacques.On the relationship between the twin internal structure and the work-hardening rate of TWIP steels. Scripta Materialia.2010;63(10):961-964.

[11] A. Belyakov, D. Molodov, A. Kalinenko, P. Kusakin,R. Kaibyshev.Microstructure and Mechanical Properties of a High-Mn TWIP Steel Subjected to Cold Rolling and Annealing.Metals. 2017;7(12):571.

[12] K. H. So, J. S. Kim, Y. S. Chun, K. T. Park, Y. K. Lee,C. S. Lee. Hydrogen Delayed Fracture Properties and Internal Hydrogen Behavior of a Fe-18Mn-1.5Al-0.6C TWIP Steel.Isij International.2009; 49(12):1952-1959.

[13] O. Bouaziz, S. Allain, C. P. Scott, P. Cugy,D. Barbier.High manganese austenitic twinning induced plasticity steels: A review of the microstructure properties relationships.Current Opinion in Solid State and Materials Science. 2011;15(4):141168.

[14] C. Beal, X. Kleber, D. Fabregue, M. Bouzekri.Embrittlement of a zinc coated high manganese TWIP steel.Materials Science and Engineering A. 2012;543: 76-83.

[15] H. Kagechika.Recent progress and future trends in the research and development of steel.NKK Technical Review(Japan).2003;88(88):6-9.

[16] Y. Sakumoto.Recent Trends and Future Direction in the Technology for Structural 
Steels Used in Buildings.2008;97:8-10.

[17] M. H. Shahavi, M. Hosseini, M. Jahanshahi, R. L. Meyer,G. N. Darzi.Clove oil nanoemulsion as an effective antibacterial agent: Taguchi optimization method.Desalination and Water Treatment.2016;57(39):18379-18390.

[18] S. A. Rizvi, S. P. Tewari. Optimization of gas metal arcwelding parameters of SS304 austenitic steel by Taguchi -grey relational analysis. Journal of Computational and Applied Research in Mechanical Engineering.2018;7(2):,189-198.

[19] Saadat Ali Rizvi, SP Tewari, Wajahat Ali, "Application of Taguchi technique to optimize the process parameters of MIG wedging on IS2062 steel, International Journal on Emerging Trends in Mechanical \& Production Engineering,Vol. 2, Issue $2-2016,1-11$

[20] N. Ghosh, P. K. Pal, G. Nandi. Parametric Optimization of MIG Welding on 316L Austenitic Stainless Steel by Grey-based Taguchi Method.Procedia Technology.2016;25:1038-1048.

[21] S. Datta, A. Bandyopadhyay, P. K. Pal. Grey-based taguchi method for optimization of bead geometry in submerged arc bead-on-plate welding. International Journal of Advanced Manufacturing Technology.2008;39:1136-1143.

[22] M. Korzeniowski, T. Piwowarczyk, P. Kustroń, A. Czubak.Low-Energy Welding Methods Used For Semi-Automatic Thin-Walled Automotive Steels.Advances in Materials Science.2013;13(3):17-25.

[23] N. Knopp, R. Killing. Arc brazing - Innovative , safe and economical.welding GmbH.2003;WM023401;08.03:1-8.

[24] Y. Miyazaki.Tensile Shear Strength of Laser Welded Lap Joints.Nippon Steel Technical Report.2007;95:28-34.

[25] K. R. Jagtap, M. S. Rojekar, S. V. Dravid, A. R. Deshpande.Effect of Welding Parameters on Tensile \& Yield Strength of IS 2062 grade Steel Using Design of Experiment Approach.Materials Today: Proceedings.2017;4(8):7875-7883.

[26] K.-S. Bang, D.-H. Jung, C. Park, W.-S. Chang. Effects of welding parameters on tensile strength of weld metal in flux cored arc welding.Science and Technology of Welding and Joining.2008;13(6):509-514. 